\title{
Pengaruh Pola Asuh terhadap Kualitas Hidup Siswa Pelaku Tawuran
}

\author{
Agustina $^{1}$, Yeni Anna Appulembang ${ }^{2}$ \\ ${ }^{1}$ Fakultas Psikologi, Universitas Tarumanagara \\ Email: agustina@fpsi.untar.ac.id \\ ${ }^{2}$ Fakultas Psikologi, Universitas Tarumanagara \\ Email: yennia@fpsi.untar.ac.id
}

\begin{abstract}
ABSTRAK
Tawuran merupakan salah satu fenomena yang banyak terjadi di kalangan remaja. Menurut Gunarsa (2004) karakteristik masa remaja adalah keadaan emosi yang labil, membentuk kegiatan secara berkelompok dan keinginan untuk menjelajahi lingkungan Pada masa remaja ini, remaja seolah lepas dari peran orangtua dan lebih mandiri dalam melakukan keputusan sendiri. Orangtua sebagai bagian dalam kehidupan remaja memiliki peranan tertentu, salah satunya diwujudkan dalam bentuk pola asuh. Baumrind (1991) mengembangkan empat tipe pola asuh yang menggambarkan bagaimana orangtua dapat mengkombinasikan pengasuhan anak dan batas aturan dalam keluarga yaitu: authoritarian, authoritative, neglectful, dan indulgent. Setiap pola asuh dapat menghasilkan karakteristik yang berbeda-beda pada masing-masing anak (Sari, 2007). Penerapan pola asuh yang tepat, tidak akan membawa perkembangan yang buruk bagi anak. Perilaku tawuran merupakan suatu perilaku yang menyimpang dan cenderung dilakukan secara berkelompok. Karena dilakukan secara berkelompok, maka perilaku ini dapat mempengaruhi kualitas hidup pada remaja. Penelitian ini bertujuan untuk mengetahui perbedaan kualitas hidup ditinjau dari pola asuh orangtua pada siswa pelaku tawuran. Penelitian ini menggunakan metode kuantitatif dengan melibatkan 309 subyek penelitian yang berjenis kelamin laki-laki. Berdasarkan hasil penelitian, diketahui bahwa terdapat perbedaan kualitas hidup ditinjau dari pola asuh ayah maupun ibu pada siswa pelaku tawuran, dengan nilai $p<0,05$ dimana $p$ value sebesar 0,000.
\end{abstract}

Kata Kunci: tawuran, pola asuh, kualitas hidup

\section{PENDAHULUAN}

Tawuran merupakan salah satu fenomena yang menarik untuk dibahas. Berdasarkan berita dari Sindonews (Arjawinangun, 2014), terjadi kenaikan yang pesat pada pelajar di Jakarta yang melakukan tawuran dalam rentan waktu dari 2010-2013. Pada tahun 2010 terdapat 102 kasus tawuran dan tahun 2011 mengalami penurunan menjadi sekitar 96 kasus. Pada tahun 2012 kasus tawuran kembali meningkat dari tahun 2011. Kasus ini meningkat tajam dengan kenaikan sebanyak 44\% dari tahun 2012. Jumlah kasus tawuran berdasarkan perhitungan persentasi tahun 2013 sebanyak 229 kasus, sedangkan di tahun 2012 hanya 101 kasus, dalam kasus ini 19 siswa meninggal dunia. Menurut Arist, "Tanpa adanya penanganan yang serius dari semua pihak, dikhawatirkan fenomena ini akan terus memakan korban. Lama-lama generasi penerus bangsa akan berguguran" ujarnya kepada wartawan di Komnas PA (dalam Arjawinangun, 2014).

Tawuran ini banyak terjadi di kalangan remaja. Masa remaja merupakan masa peralihan dari masa anak-anak menuju masa dewasa yang terjadi dalam rentang usia 12-20 tahun (Papalia \& Martorell, 2012). Menurut Gunarsa (2004) karakteristik masa remaja adalah keadaan emosi yang labil, membentuk kegiatan secara berkelompok dan keinginan untuk menjelajahi lingkungan. Remaja juga mengutamakan peergroup sahabat mereka daripada peran dari orang tua. Prienstein (dalam Santrock, 2011) mengatakan remaja cenderung akan menyesuaikan diri dengan kelompok pergaulannya apabila mereka tidak memiliki keyakinan terhadap identitas sosialnya.

Orang tua sebagai bagian dalam kehidupan remaja memiliki peranan tertentu. Menurut Parke dan Buriel (dalam Santrock, 2011), orang tua memiliki peran dalam mengatur kesempatan yang ada bagi remaja yaitu, dengan mengawasi hubungan remaja dan berperan sebagai inisiator sosial. Hal ini dikarenakan, pertama kali individu mengenal norma-norma dan nilai-nilai masyarakat umum berasal dari norma-norma dan nilai-nilai yang berlaku dalam keluarganya yang 
merupakan lingkungan primer bagi individu tersebut (Sarwono, 2008). Menurut Offer dan Church (dalam Papalia \& Martorell, 2012), meskipun remaja sudah mengembangkan interaksi sosial dengan teman sebaya, mereka tetap membutuhkan orang tua mereka untuk dasar keamanannya.

Salah satu aspek yang berperan penting dalam perkembangan anak adalah pola asuh yang diterapkan oleh orangtua kepada anak dan akan membentuk perilaku anak ketika tumbuh menjadi remaja. Menurut Baumrind (1991), pola asuh orangtua adalah suatu cara bagaimana orangtua mengasuh dan mendidik anak. Pola asuh orangtua juga merupakan bentuk dan proses interaksi yang terjadi antara orangtua dan anak dalam keluarga yang akan memberi pengaruh terhadap perkembangan kepribadian anak (Baumrind dalam Irmawati, 2002). Baumrind (1991) mengemukakan dua dimensi mayor pola pengasuhan orang tua, yaitu demandingness dan responsiveness.Dimensi responsiveness/acceptance mencakup aspek penerimaan (nurturance) dan komunikasi antara orang tua dan anak (parent-child communication). Dimensi ini memperlihatkan seberapa besar orang tua bersikap mendukung dan peka terhadap kebutuhan anak serta kesediaan untuk memberikan kasih sayang dan pujian ketika mereka berhasil mencapai harapannya.

Baumrind (1991) menggunakan dua dimensi ini untuk mengembangkan empat tipe pola asuh yang menggambarkan bagaimana orangtua dapat mengkombinasikan pengasuhan anak dan batas aturan dalam keluarga yaitu: authoritarian, authoritative, neglectful, dan indulgent. Pola asuh authoritarian merupakan pola asuh yang menekankan pada tindakan menghukum dan menetapkan banyak batasan, dimana orang tua mengharuskan anak mengikuti perintah orang tua dan menghargai pekerjaan dan usaha. Pola asuh authoritative merupakan pola asuh yang menekankan pada usaha mendorong anak untuk dapat menjadi mandiri, namun tetap memberikan batasan dan pengawasan. Pola asuh neglectful merupakan pola asuh dimana orang tua sama sekali tidak melibatkan diri dalam kehidupan anak-anaknya (Santrock, 2008). Pola asuh indulgent merupakan pola asuh yang menekankan pada pemberian kebebasan pada anak atas apapun kemauan ataupun pilihan mereka. Anak-anak tidak belajar mengontrol diri mereka karena orang tua tidak memperhitungkan keseluruhan perkembangan anak-anak mereka (Santrock, 2008).

Setiap pola asuh menghasilkan karakteristik yang berbeda-beda pada masing-masing anak (Sari, 2007). Sejalan dengan hal ini, Ramadhan (2009) menyebutkan bahwa pola asuh antara satu orang tua dengan orang tua lainnya juga akan berbeda. Penerapan pola asuh yang tepat, tidak akan membawa perkembangan yang buruk bagi anak. Berdasarkan penelitian yang dilakukan oleh Aran, Shalev, Biran, dan Gross-Tsur (2007) diketahui bahwa pola asuh merupakan faktor yang signifikan terhadap kualitas hidup pada anak dengan cerebral palsy. Bahkan pola asuh memiliki pengaruh lebih tinggi dibandingkan tingkat keparahan penyakit tersebut pada aspek psikososial anak dengan cerebral palsy. Lebih tinggi dibandingkan faktor-faktor lainnya yang juga diteliti seperti IQ, kecemasan, dan sosial ekonomi (Aran et al., 2007).

Kualitas hidup dapat diartikan sebagai suatu pencapaian terhadap sesuatu yang ideal atau yang sesuai dengan keinginannya (Diener \& Suh, dalam Kahneman, Diener, \& Schwarz, 1999 dalam Nofitri, 2009). Saat istilah kualitas hidup pertama kali diperkenalkan pada tahun 1980-an, bertujuan untuk mengukur dampak dari masalah kesehatan terhadap kehidupan sehari-hari seseorang (Power, dalam Efklides, Anastasia, Moraitou, \& Despina, 2012). Sejak saat itu, istilah ini digunakan untuk mencakup segala aspek dari kehidupan manusia, misalnya kesehatan fisik dan keadaan psikologis (kognitif dan emosional), hubungan sosial, kondisi ekonomi, 
kemungkinan rekreasional, dan kehidupan pekerjaan. Koot dan Wallander (2001) menyebutkan bahwa kualitas hidupmerupakan kombinasi dari kesejahteraan dalam berbagai aspek yang menonjol pada suatu zaman dan kebudayaan seseorang yang dinilai secara objektif dan subjektif, tetapi tetap mengikuti standar universal dari hak asasi manusia. Berdasarkan WHOQOL-BREF (dalam Lopez \& Snyder, 2003) quality of life memiliki empat dimensi, yaitu kesehatan fisik, kesehatan psikologis, hubungan sosial, dan hubungan dengan lingkungan.

Berdasarkan fenomena yang dipaparkan sebelumnya, diketahui bahwa perilaku tawuran merupakan suatu perilaku yang menyimpang dan cenderung dilakukan secara berkelompok. Karena dilakukan secara berkelompok, maka berhubungan dengan dimensi hubungan sosial pada kualitas hidup. Oleh karena itu, masalah yang timbul pada masa remaja, seperti perilaku tawuran dapat mempengaruhi kualitas hidup pada remaja yang dalam hal ini adalah siswa pelaku tawuran. Dengan demikian, dibutuhkan pola asuh yang tepat dari orang tua agar para remaja ini dapat memiliki kualitas hidup yang baik. Hal inilah yang membuat peneliti tertarik untuk mengetahui lebih lanjut mengenai perbedaan kualitas hidup pada siswa pelaku tawuran ini ditinjau dari pola asuh orang tua mereka. Mengingat kualitas hidup merupakan seuatu yang penting dalam hidup setiap individu.

\section{METODE PENELITIAN \\ Partisipan penelitian}

Partisipan dalam penelitian ini adalah remaja yang duduk dibangku SMA/SMK di Makassar,berjenis kelamin laki-laki dan perempuan, serta pernah melakukan tawuran. Sampel yang digunakan pada penelitian ini berjumlah 309 orang. Teknik pengambilan sampel dengan menggunakan purposive sampling.

\section{Instrumen penelitian}

Pada penelitian ini, alat ukur yang digunakan ada dua yaitu Pola Asuh dan Quality of Life. Pada alat ukur pola asuh peneliti menggunakan dari alat ukur yang dikembangkan oleh Chandra dan Suyasa (2006) dengan berlandaskan teori Baumrind (1991). alat ukur pola asuh orangtua terdiri atas dua jenis yaitu pola asuh ibu dan pola asuh ayah. Masing-masing terdiri atas dimensi yaitu acceptance/responsiveness dan demandingness/control.Dari dua dimensi ini yang akan membentuk empat (4) jenis pola asuh yaitu authoritarian, authoritative, permissive, dan neglect. Alat ukur ini memiliki 34 butir pernyataan dengan skala Likert yang dibagi menjadi empat (4) pilihan, yaitu $1=\mathrm{STS}, 2=\mathrm{SS}, 3=\mathrm{TS}$, dan $4=\mathrm{STS}$

Alat ukur kedua adalah quality of life (QOL). Alat ukur ini dikembangkan oleh Christina (2015). berdasarkan dimensi WHOQOL-BREF. Alat ukur ini memiliki 30 butir pernyataan dengan skala Likert yang dibagi menjadi empat (4) pilihan, yaitu $1=\mathrm{STS}, 2=\mathrm{SS}, 3=\mathrm{TS}$, dan $4=\mathrm{STS}$. Butirbutir tersebut dibagi menjadi 15 butir positif dan 15 butir negatif dan dibagi menjadi empat dimensi quality of life. Dimensi-dimensi tersebut adalah kesehatan fisik, kesehatan psikologis, hubungan sosial, dan hubungan dengan lingkungan. Semakin tinggi skor yang didapatkan oleh subyek pada kuesioner ini, maka semakin tinggi juga quality of life subyek tersebut.

\section{Teknik pengolahan data}

Pada penelitian ini, peneliti melakukan analisis data statistik dengan menggunakan Kruskal Wallis untuk melakukan uji perbedaan quality of life siswa yang melakukan tawuran ditinjau dari pola asuh orangtuanya. 


\section{HASIL DAN PEMBAHASAN}

Gambaran umum subyek berdasarkan jenis kelamin

Pada penelitian ini, yang menjadi subyek penelitian terakhir adalah laki-laki sebanyak 309 orang.

Tabel 1. Gambaran Data Jenis Kelamin Subyek Penelitian

\begin{tabular}{lcc}
\hline Jenis kelamin & Frekuensi & Persentase \\
\hline Pria & 309 & $100 \%$ \\
\hline Total & 309 & $100 \%$ \\
\hline
\end{tabular}

Gambaran umum subyek berdasarkan usia

Berdasarkan kategori usia, subyek yang berusia 14 tahun sebanyak 2 orang atau 1,8\%, subyek yang berusia 15 tahun sebanyak 106 orang atau 34,3\%, subyek yang berusia 16 tahun sebanyak 94 orang atau 30,4\%, subyek yang berusia 17 tahun sebanyak 74 orang atau 23,9\%, subyek yang berusia 18 tahun sebanyak 25 orang atau 8,1\%, subyek yang berusia 19 tahun sebanyak 8 orang atau 2,6\%. Gambaran data usia subyek dapat dilihat pada tabel 2.

Tabel 2. Gambaran Data Usia Subyek Penelitian

\begin{tabular}{lll}
\hline Usia & Frekuensi & Persentase \\
\hline 14 & 2 & $0,6 \%$ \\
15 & 106 & $34,3 \%$ \\
16 & 94 & $30,4 \%$ \\
17 & 74 & $23,9 \%$ \\
18 & 25 & $8,1 \%$ \\
19 & 8 & $2,6 \%$ \\
\hline Total & 309 & $100 \%$ \\
\hline
\end{tabular}

Uji normalitas variabel quality of life

Berdasarkan uji one sample $K-S$, maka diperoleh hasil variabel quality of life berdistribusi tidak normal (nonparametrik). Hal ini menunjukkan nilai $p$ pada pengujian Kolmogorov-Smirnov yang lebih kecil dari $0.05(0.000<0.05)$. Gambaran yang lebih jelas dapat dilihat pada Tabel 3.

Tabel 3. Hasil Uji Normalitas Variabel Quality of Life

\begin{tabular}{lcc}
\hline Variabel & Kolmogorov-Smirnov $\boldsymbol{Z}$ & $\boldsymbol{P}$ \\
\hline Quality of Life & 2,168 & 0.000 \\
\hline
\end{tabular}

\section{Uji beda quality of life ditinjau dari pola asuh ayah}

Pada penelitian ini, peneliti ingin melihat perbedaan quality of life ditinjau dari pola asuh ayah dengan menggunakan empat jenis pola asuh (authoritative, authoritarian, permissive, dan neglect).

Berdasarkan hasil analisis data dengan menggunakan Kruskal Wallis, maka menunjukkan nilai Chi Square 43,559, dan nilai $p=0,000<0,05$. Hal ini berarti terdapat perbedaan kualitas hidup pada remaja yang melakukan tawuran ditinjau dari pola asuh ayah. Untuk lebih jelas dapat pada Tabel 4. 
Tabel 4. Uji Beda Quality of Life ditinjau dari Pola Asuh Ayah

\begin{tabular}{ccc}
\hline Variabel Dependen & Variabel Independen & $\boldsymbol{P}$ \\
\hline Quality of life & Pola asuh Ayah & 0.000 \\
\hline
\end{tabular}

\section{Uji beda quality of life ditinjau dari pola asuh ibu}

Pada penelitian ini, peneliti ingin melihat perbedaan quality of life ditinjau dari pola asuh ibu dengan menggunakan empat jenis pola asuh (authoritative, authoritarian, permissive dan neglect).

Berdasarkan hasil analisis data dengan menggunakan Kruskal Wallis, maka menunjukkan nilai Chi Square 63,343, dan nilai $\mathrm{p}=0,000<0,05$. Hal ini berarti terdapat perbedaan kualitas hidup pada remaja yang melakukan tawuran ditinjau dari pola asuh ibu. Untuk lebih jelas dapat pada Tabel 5.

Tabel 5. Uji Beda Quality of Life ditinjau dari Pola Asuh Ibu

\begin{tabular}{ccc}
\hline Variabel Dependen & Variabel Independen & $\boldsymbol{P}$ \\
\hline Quality of life & Pola asuh Ibu & 0.000 \\
\hline
\end{tabular}

Dengan demikian, dapat dikatakan bahwa hasil penelitian ini sejalan dengan hasil penelitian yang dilakukan oleh Aran, Shalev, Biran, dan Gross-Tsur (2007) yang menemukan bahwa pola asuh merupakan faktor yang signifikan terhadap kualitas hidup pada anak dengan cerebral palsy. Offer dan Church (dalam Papalia \& Martorell, 2012) juga mengatakan bahwa meskipun remaja sudah mengembangkan interaksi sosial dengan teman sebaya, mereka tetap membutuhkan orang tua mereka untuk dasar keamanannya.

Sebagian besar subyek penelitian memiliki pola asuh Ayah yang authoritative dan neglectful. Terkait dengan pola asuh ini, sebagian besar subyek memiliki Ayah yang bekerja di luar rumah, sehingga sebagian besar waktunya berada di luar rumah. Dengan demikian pengasuhan lebih banyak dilakukan oleh Ibunya yang merupakan ibu rumah tangga, yang kebanyakan menghabiskan waktu di dalam rumah mengurus keperluan rumah tangga dan anak. Sedangkan pola asuh Ibu yang paling banyak adalah authoritarian. Pola asuh authoritarian merupakan pola asuh yang menekankan pada tindakan menghukum dan menetapkan banyak batasan, dimana orang tua mengharuskan anak mengikuti perintah orang tua dan menghargai pekerjaan dan usaha (Baumrind, 1991).Anak dengan pola asuh authoritarian biasanya memiliki pencapaian akademis dan kecakapan sosial yang rata-rata. Mereka juga memiliki self-esteem yang rendah, tidak puas terhadap dirinya, seringkali menarik diri, tidak spontan, tidak tertarik pada pengalamanpengalaman baru, curiga, cemas, dan sulit mengatur emosinya (Papalia \& Martorell, 2012). Anak juga kurang dapat melakukan penyesuaian dan lebih cenderung terlibat dalam tindakan antisosial (Berk, 2003).

\section{KESIMPULAN}

Berdasarkan hasil penelitian dapat ditarik kesimpulan bahwa terdapat perbedaan kualitas hidup ditinjau dari pola asuh orang tua pada siswa pelaku tawuran. Sebagian besar subyek penelitian memiliki pola asuh Ayah yang authoritative dan neglectful. Sedangkan pola asuh Ibu yang paling banyak adalah authoritarian. 
Penelitian ini memiliki keterbatasan dalam teori mengenai kualitas hidup. Bahasan mengenai kualitas hidup masih kurang mendalam dikarenakan penelitian mengenai kualitas hidup yang terkait penelitian ini masih terbatas. Selain itu, perlu dipertimbangkan pula mengenai jumlah subyek. Jika jumlah subyek lebih banyak, maka data yang didapatkan diharapkan akan lebih banyak.

\section{Acknowledgement}

Penelitian ini dibiayai oleh Direktorat Penelitian dan Pengabdian Kepada Masyarakat, Universitas Tarumanagara.

\section{REFERENSI}

Agustina \& Risnawaty, W. (2015). Pengembangan alat ukur the family quality of life scale. Jakarta: Lembaga Penelitian dan Publikasi Ilmiah Universitas Tarumanagara. Unpublished.

Aprilia, N. \& Indrijati, H. (2014). Hubungan antara kecerdasan emosi dengan perilaku tawuran pada remaja laki-laki yang pernah terlibat tawuran di SMK "B” jakarta. Jurnal Psikologi Pendidikan dan Perkembangan, 3(1),1-11.

Aran, A., Shalev, R., S., Biran, G. \& Gross-Tsur, V. (2007). Parenting styles impacts on quality of life in children with cerebral palsy. Zedek Medical Center. doi: 10.1016/j.jpeds.2007.02.011.

Arjawinangun, K. B. (2014). 2.737 aduan, tawuran paling disoroti sepanjang 2014. Diakses pada 13 April 2015, dari http://metro.sindonews.com/read/943991/31/2-737-aduan-tawuranpaling-disoroti-sepanjang-2014-1419924767.

Baumrind, D. (1991). The influence of parenting style on adolescent competence and subtance use. Journal of Early Adolescence, 11(1), 56-95.

Berk, L. E. (2003). Child development. New York: Allyn \& Bacon.

Chandra, R. \& Suyasa, P. T. Y. S. (2006). Alat ukur pola asuh orangtua. Bagian Riset dan Pengukuran, Fakultas Psikologi, Universitas Tarumanagara, Jakarta. (Dokumen alat ukur tidak diterbitkan).

Departemen Pendidikan Nasional. (2008). Kamus besar bahasa indonesia (edisi keempat). Jakarta: PT Gramedia Pustaka Utama.

Efklides, Anastasia, Moraitou, \& Despina. (2012). A positive psychology perspective on quality of life. Heidelberg: Springer Science \& Business Media.

Gunarsa, S.D \& Gunarsa, Y. S. D. (2004). Dari anak sampai usia lanjut: Bunga rampai psikologi anak. Jakarta: Gunung Mulia.

Irmawati. (2002). Motivasi berprestasi dan pola pengasuhan suku bangsa batak. Jakarta: Fakultas Pasca Sarjana UI.

Koot, H. M., \& Wallander, J. L. (2001). Quality of life in child and adolescent illness: Concepts, Methods and Findings. UK:Brunner-Routledge.

Nofitri (2009). Gambaran kualitas hidup penduduk dewasa pada lima wilayah di Jakarta. Jakarta: Fakultas Psikologi Universitas Indonesia.

Papalia, D. E., \& Martorell, G. (2012). Experience human development (12 ${ }^{\text {nd }}$ ed.). NY: McGrawHill.

Ramadhan. (2009). Pola asuh orang tua dalam mengarahkan perilaku anak. Diakses pada 29 Mei 2015 dari http://tarmizi.wordpress.com

Santrock, J. W. (2011). Adolescence. Boston,USA: McGraw Hill.

Sari, U. M. (2007). Perbedaan perilaku asertif pada remaja ditinjau dari pola asuh orang tua. Skripsi. Fakultas Psikologi Universitas Katolik Soegijapranata Semarang. Unpublished.

Sarwono, S.W. (2011). Psikologi remaja. Jakarta: Raja Grafindo Persada. 